Animal Biotelemetry

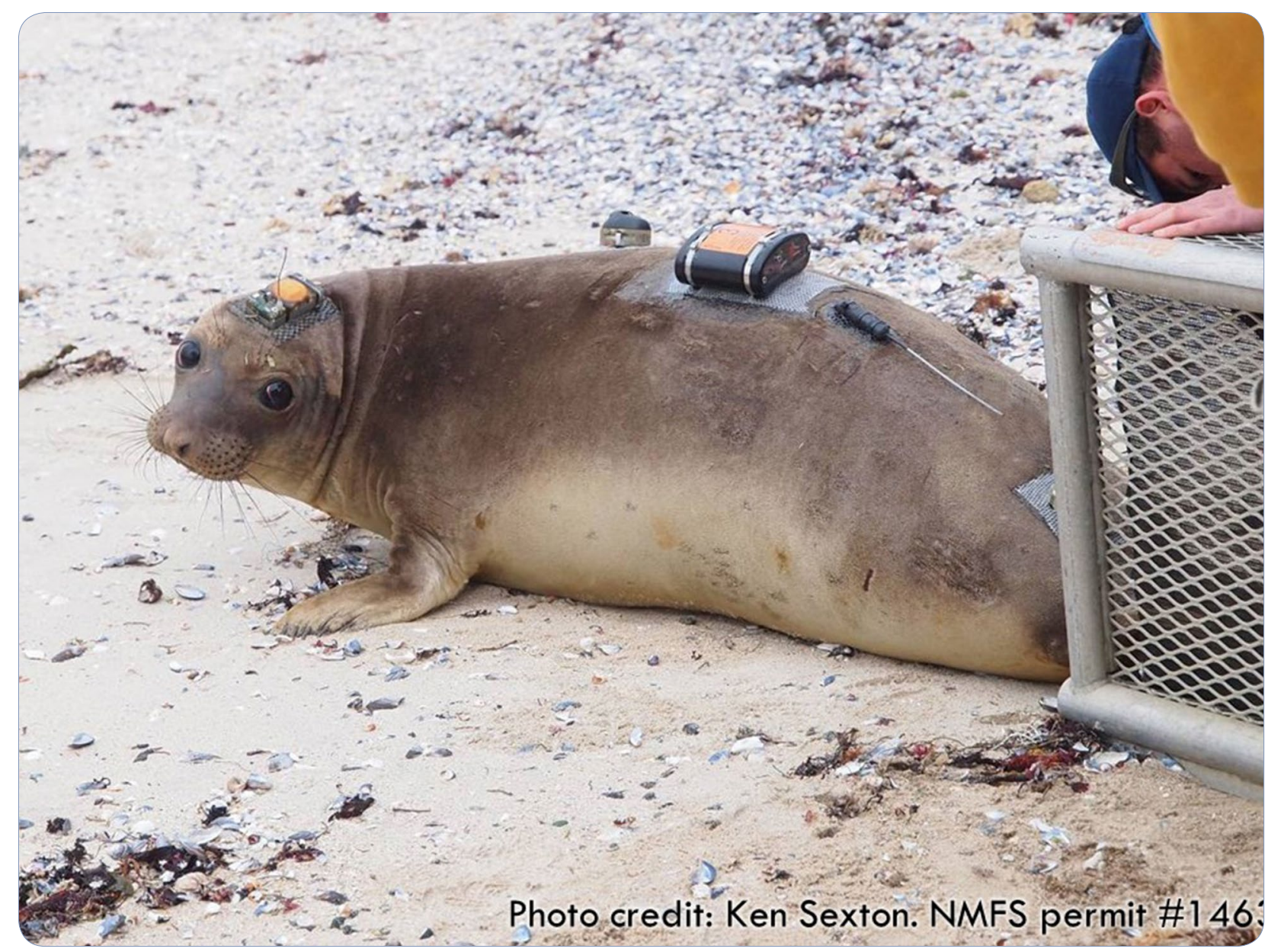

\title{
An animal-borne active acoustic tag for minimally invasive behavioral response studies on marine mammals
}

Fregosi et al. 


\title{
An animal-borne active acoustic tag for minimally invasive behavioral response studies on marine mammals
}

Selene Fregosi ${ }^{1 *} \mathbb{D}$, Holger Klinck ${ }^{1,2}$, Markus Horning ${ }^{3}$, Daniel P. Costa ${ }^{4}$, David Mann ${ }^{5}$, Kenneth Sexton ${ }^{6}$, Luis A. Hückstädt ${ }^{4}$, David K. Mellinger ${ }^{1}$ and Brandon L. Southall ${ }^{7,8}$

\begin{abstract}
Background: There is a variety of evidence that increased anthropogenic noise (e.g., shipping, explosions, sonar) has a measureable effect on marine mammal species. Observed impacts range in severity from brief interruptions of basic life functions to physiological changes, acute injury, and even death. New research tools are needed to better measure and understand the potential effects of anthropogenic noise on marine mammals. Current behavioral response studies typically utilize ship-based sound sources to study potential acute behavioral responses in tagged animals experimentally exposed to noise. Integrating the sound source within animal-mounted passive acoustic and motionsensing tags provides a novel tool for conducting additional highly controlled response studies.

Results: We developed and conducted pilot field trials of a prototype tag on five juvenile northern elephant seals, Mirounga angustirostris, using experimental exposures to both natural and anthropogenic noise stimuli. Results indicate behavioral responses were elicited in tagged individuals. However, no pattern was found in the occurrence and types of response compared to stimulus type. Responses during the ascending dive phase consisted of a dive inversion, or sustained reversal from ascending to descending (8 of 9 exposures). Dive inversions following exposure were 4-11 times larger than non-exposure inversions. Exposures received during the descending dive phase resulted in increased descent rates in 9 of 10 exposures. All 8 exposures during dives in which maximum dive depth was limited by bathymetry were characterized by increased flow noise in the audio recordings following exposure, indicating increased swim speed.
\end{abstract}

Conclusions: Results of this study demonstrate the ability of an animal-mounted sound source to elicit behavioral responses in free-ranging individuals. Behavioral responses varied by seal, dive state at time of exposure, and bathymetry, but followed an overall trend of diving deeper and steeper and swimming faster. Responses did not consistently differ based on stimulus type, which may be attributable to the unique exposure context of the very close proximity of the sound source. Further technological development and focused field efforts are needed to advance and apply these tools and methods in subsequent behavioral response studies to address specific questions.

Keywords: Acoustic, Tag, Behavioral response, Northern elephant seal, Controlled exposure experiment

\section{Background}

Marine mammals rely on acoustic cues for many life functions including navigation, foraging, communication,

\footnotetext{
*Correspondence: selene.fregosi@oregonstate.edu

${ }^{1}$ Cooperative Institute for Marine Resources Studies, Hatfield Marine

Science Center, Oregon State University and NOAA Pacific Marine

Environmental Laboratory, 2030 SE Marine Science Drive, Newport, OR

97365, USA

Full list of author information is available at the end of the article
}

and predator avoidance [1]. Anthropogenic activities have contributed to increased ocean ambient noise levels in certain areas $[2,3]$. The potential adverse effects of both acute and chronic human-generated noise on marine mammals are a major conservation concern [e.g., 4-14]. Naval sonar activities have been linked to cetacean stranding events, where necropsies have shown physical damage to vital organs $[5,6]$. Noise has also been shown 
to increase stress hormone levels [9], reduce foraging activity $[8,15]$, alter migration routes [16], mask communication sounds [10], and displace marine mammals from primary feeding and breeding grounds $[11,12,15]$. Understanding the differential responses of marine mammals to noise stimuli is necessary for managing human impacts in the ocean $[17,18]$.

Behavioral response studies (BRSs) using a controlled exposure experiment (CEE) paradigm have emerged as an effective tool to study discrete behavioral responses of individual, free-ranging marine mammals to particular sounds $[19,20]$. These studies typically use animalmounted archival motion-sensing (via pressure sensors and triaxial accelerometers and magnetometers) and acoustic recording tags as well as visual observations to measure individual focal animal response to a controlled exposure from a sound source deployed nearby. Measurements of swim speed, dive depth, dive duration, heading, vocal behavior, group spacing, ascent and descent rate, and other metrics are made before, during, and after the CEE in order to assess response [e.g., 21-25].

Combining the sound source with behavioral sensors and an acoustic recorder into a single animal-mounted tag could enable an alternative BRS methodological approach. Such an instrument could offer a more costeffective tool that would allow for better control of exposure sound levels. While the exposure context is unique in being physically attached to the animal, this context is consistent for all exposures whereas other BRS approaches often have variability in the context of different exposures. Finally, it could enable investigation of the effects of varied sound levels, multiple or sustained exposures, and behavioral habituation.

The northern elephant seal, Mirounga angustirostris [26], presents an ideal study species to test the effectiveness of such a tag. Northern elephant seals are accessible as they haul out twice a year to breed and molt [27, 28]. Elephant seal diving behavior is well studied and found to be highly stereotypic, with almost continuous, repetitive deep diving [28-31]. They regularly reach depths similar to many of the cetacean species thought to be most affected by anthropogenic noise (i.e., beaked whales; [ 28 , $32])$ and dive as deep as or deeper than the deep sound channel $(\sim 1000 \mathrm{~m})$. Previous studies have shown that carrying relatively large instruments does not inhibit the ability of juvenile seals to swim or forage, and instrument recovery rate is above $90 \%[28,33,34]$. Additionally, northern elephant seals have acute underwater hearing sensitivity with relatively low hearing thresholds occurring over a very broad frequency range [35, 36]. High-resolution behavioral responses to sound stimuli from our device can be collected for elephant seals using sensors that measure changes in pressure, acceleration, strength of magnetic field, and turn rate [13, 37].

Here we describe a pilot study testing an animalmounted active acoustic and motion-sensing tag on freeranging juvenile northern elephant seals. The main goals of this study were (1) to test whether an animal-borne acoustic tag elicits any behavioral response and if so (2) to determine whether responses are related to stimulus content. Development and application of an active acoustic tag in a behavioral response paradigm could answer targeted questions regarding the nature and magnitude of responses of marine mammals to anthropogenic noise and their potential physiological consequences, leading to better informed evaluation of human-generated sound.

\section{Methods}

\section{Tag development}

The prototype tag contained three subsystems: an active acoustic playback system, a passive acoustic recording system, and a motion monitoring system (Fig. 1). An OpenTag single board controller (SBC, Loggerhead Instruments, Inc, Sarasota, FL, USA) controlled playbacks and contained a three-axis accelerometer, magnetometer, and gyroscope. It was programmed (Loggerhead Instruments, Arduino programming language) to execute a playback of a single stimulus at a predetermined time interval, using sound files stored on a SOMO playback module (4D Systems, Minchinbury, NSW, Australia), through an amplifier board (LM48580 Evaluation Board, Texas Instruments, Dallas, TX, USA) and two or three piezo electric ceramic cylinder transducers (Steiner \& Martin, Inc, Doral, FL, USA; $26 \mathrm{~mm}$ external diameter $\times 22$ internal diameter $\times 13 \mathrm{~mm}$ high, resonant frequency $43 \pm 1.5 \mathrm{kHz}$ ). The playback system was powered by a $3.7 \mathrm{~V}, 3000 \mathrm{mAh}$ lithium-ion polymer rechargeable battery (Tenergy, Fremont, CA, USA).

Six playback stimuli were used: sperm whale (Physeter macrocephalus) clicks, common dolphin (Delphinus sp.) whistles, killer whale (Orcinus orca) whistles and clicks, simulated mid-frequency active sonar, and white noise. White noise and the simulated mid-frequency sonar were created using Adobe Audition 3 (Adobe System Incorporated, San Jose, CA, USA). Sperm whale clicks and common dolphin whistles were obtained from the Discovery of Sound in the Sea sound library. ${ }^{1}$ Both killer whale vocalizations were obtained from the Vancouver Aquarium. ${ }^{2}$ An inverse of the transducer's transmitting sensitivity function was generated and used to normalize each playback's output over the entire frequency bandwidth.

\footnotetext{
${ }^{1}$ http://www.dosits.org/audio/marinemammals/toothedwhales/.

${ }^{2}$ http://killerwhale.vanaqua.org/page.aspx?pid=1331.
} 


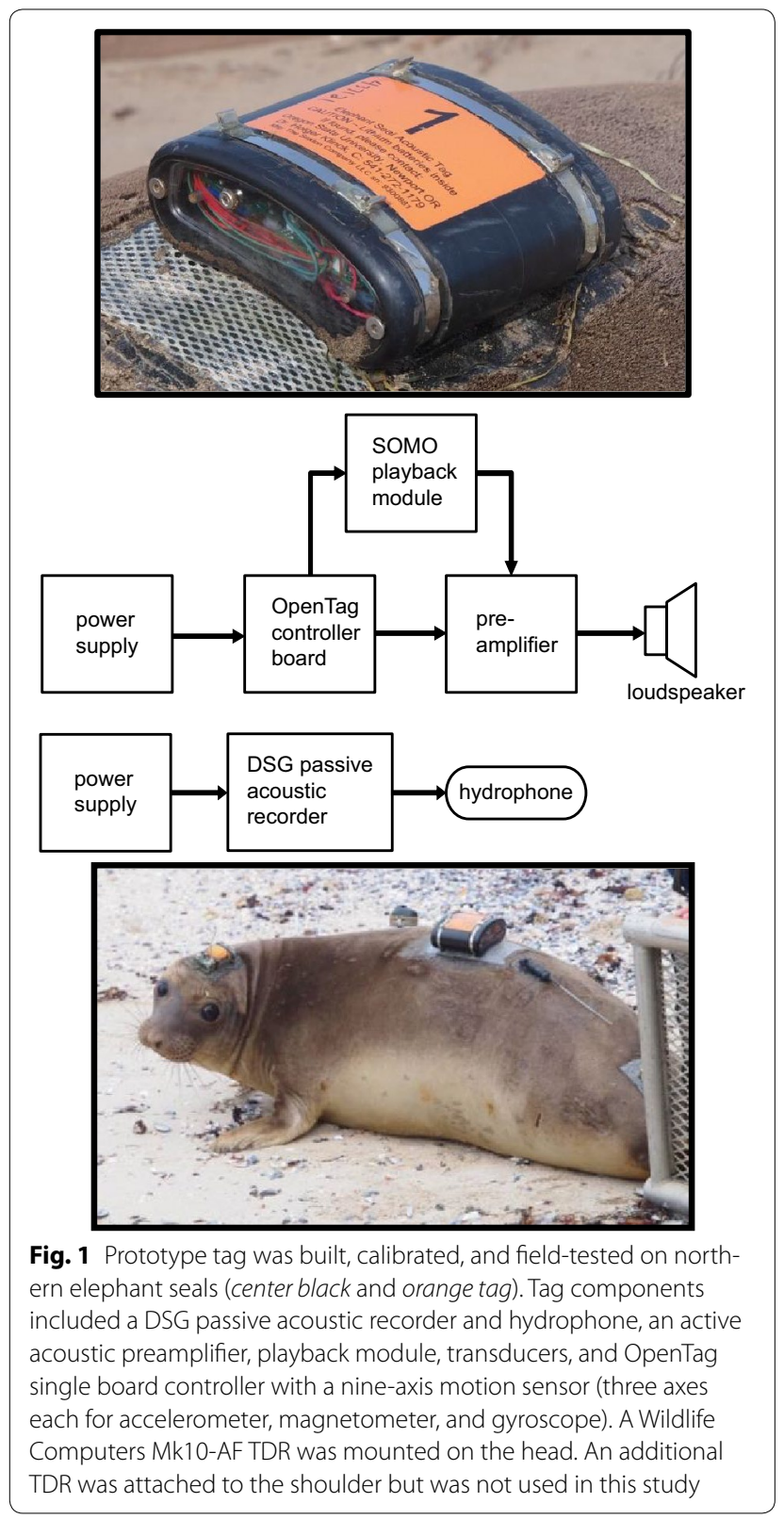

Playbacks of stimuli were limited to $30 \mathrm{~s}$ to reduce the possibility of seals associating the stimulus with the device mounted on their back. Playback track source levels were measured using a calibrated hydrophone system (G.R.A.S. 42AC High Pressure Pistonphone, G.R.A.S. Sound \& Vibration A/S, Holte, Denmark) and ranged from 121 to $132 \mathrm{~dB}$ re $1 \mu \mathrm{Pa}$ at $1 \mathrm{~m}$, depending on exposure type (Table 1). Estimated received levels were calculated assuming spherical spreading, based on the distance of tag from the animals' ears.

A DSG acoustic recorder (Loggerhead Instruments, Inc, Sarasota, FL, USA) connected to an HTI-96-MIN
Table 1 Calibrated source levels for exposure stimuli

\begin{tabular}{ll}
\hline Stimulus & Source level \\
\hline White noise & $125.56(0.94) @ 1 \mathrm{~m}\left(\mathrm{~dB}_{\mathrm{RMS}}\right.$ re $\left.1 \mu \mathrm{Pa}\right)$ \\
Common dolphin whistles & $130.66(1.48) @ 1 \mathrm{~m}\left(\mathrm{~dB}_{\mathrm{RMS}}\right.$ re $\left.1 \mu \mathrm{Pa}\right)$ \\
Sperm whale clicks & \\
Killer whale whistles & $131.77(1.89) @ 1 \mathrm{~m}\left(\mathrm{~dB}_{\text {0-peak }}\right.$ re $\left.1 \mu \mathrm{Pa}\right)$ \\
Killer whale clicks & $121.06(4.60) @ 1 \mathrm{~m}\left(\mathrm{~dB}_{\mathrm{RMS}}\right.$ re $\left.1 \mu \mathrm{Pa}\right)$ \\
Sonar & Estimated 126 @ $1 \mathrm{~m}\left(\mathrm{~dB}_{0-\text { peak }}\right.$ re $\left.1 \mu \mathrm{Pa}\right)$ \\
\hline
\end{tabular}

Mean and standard deviation of two calibrated recordings are given. All sources levels are given in $\mathrm{dB}_{\mathrm{RMS}}$ re $1 \mu \mathrm{Pa} @ 1 \mathrm{~m}$ over the stimulus duration, except for the sperm whale click track ${ }^{a}$, which was measured in $\mathrm{dB}_{0 \text {-peak }}$ re $1 \mu \mathrm{Pa} @ 1 \mathrm{~m}$ and the killer whale click track ${ }^{\mathrm{b}}$ which was measured by relative comparison to killer whale whistles

hydrophone (High Tech, Inc, Long Beach, MS, USA; sensitivity $-190.5 \mathrm{~dB}$ re $1 \mathrm{~V} \mu \mathrm{Pa}^{-1}$; frequency response $2 \mathrm{~Hz}-30 \mathrm{kHz}$ ) recorded for 30 min starting 15 min prior to each scheduled playback. This provided a recorded confirmation that a single playback occurred and allowed detection of other environmental noise events occurring at the time of the playback. Recordings were sampled at $32 \mathrm{kHz}$ (16 bit resolution) with $20 \mathrm{~dB}$ of gain. The passive acoustic system was powered by a second $3.7 \mathrm{~V}$, $3000 \mathrm{mAh}$ lithium-ion polymer battery (Tenergy, Fremont, CA, USA).

All tag components were placed in an oil-filled Delrin ${ }^{\circledR}$ housing, rated to $1500 \mathrm{~m}$ depth. Clear, food-grade mineral oil was used as a non-compressible and non-conductive filler so no air remained in the housing and to limit acoustic impedance between the tag and seawater. The tag package weighed approximately $1.5 \mathrm{~kg}(<1.2 \%$ total body mass of smallest seal) and was slightly negatively buoyant. The original tag design was modified following the first three deployments. Changes in pressure and temperature between the surface and at depth caused changes in mineral oil density. The slight flexibility of Delrin ${ }^{\circledR}$ caused a pumping action to develop that moved seawater past the o-ring seals into the oil-filled tag body. Larger o-rings were used, and flexible tubing with small air pockets was attached to the outside of the housing to allow minor changes in mineral oil density and limit seawater intrusion.

\section{Field efforts}

We conducted field experiments in March and April 2012 on juvenile northern elephant seals at Año Nuevo State Park, San Mateo County, CA, USA (Fig. 2; Table 2). Seals were instrumented with the active acoustic tag placed on the animal's back (30-60 cm from the ears) and an ARGOS-Fastloc GPS time-depth recorder (TDR) on the head (Mk10-AF, Wildlife Computers, Redmond, WA, USA). Tags were attached by gluing a flexible mesh 


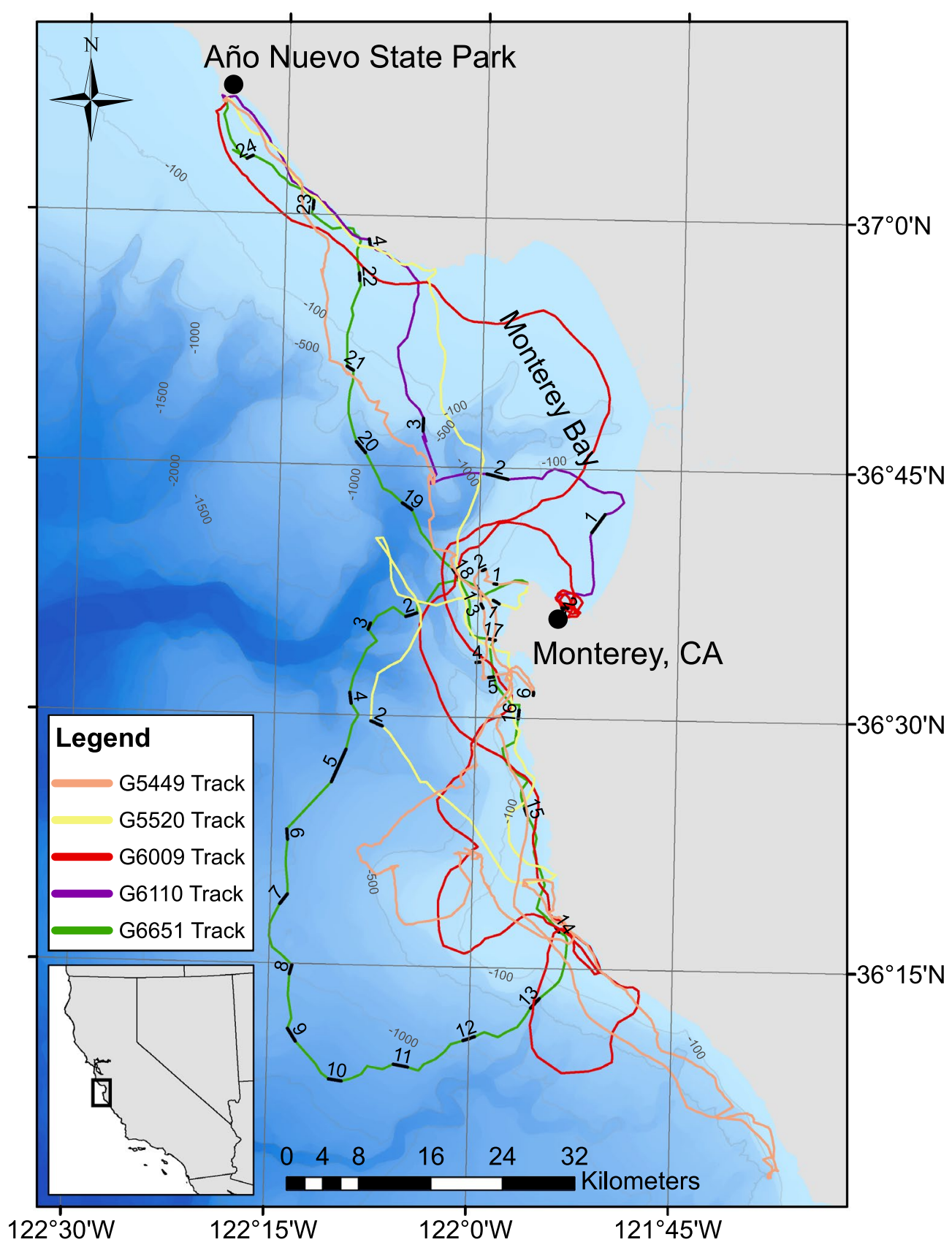

Fig. 2 Tracks of all successful seal deployments. The track line is the straight-line connection between subsequent surface locations. Numbered black bars are approximate locations where exposures occurred, between the surface locations before and after the time of the exposure. Bathymetry data are from NOAA's National Geophysical Data Center (NGDC), Southern California Coastal Relief Map, one-arc second resolution

base to the animal's fur using quick-cure adhesive (Devcon 14270-5 Minute ${ }^{\circledR}$ Epoxy, ITW Polymers Adhesives North America, Danvers, MA, USA), weaving stainless steel locking ties through the mesh, and securing the tag with the locking ties (similar to [30, 38]). Animals were transported approximately $100 \mathrm{~km}$ south to Monterey,
CA, USA, and released. Seals were recaptured upon return to Año Nuevo, and tags (including the metal ties) were manually removed from the flexible mesh base. Seals molted off the base shortly after tag recovery. Depth was sampled every $1 \mathrm{~s}$ for seal G5449 and every $4 \mathrm{~s}$ for all other seals. Resolution of TDRs were $0.5 \mathrm{~m}$ and accuracy 


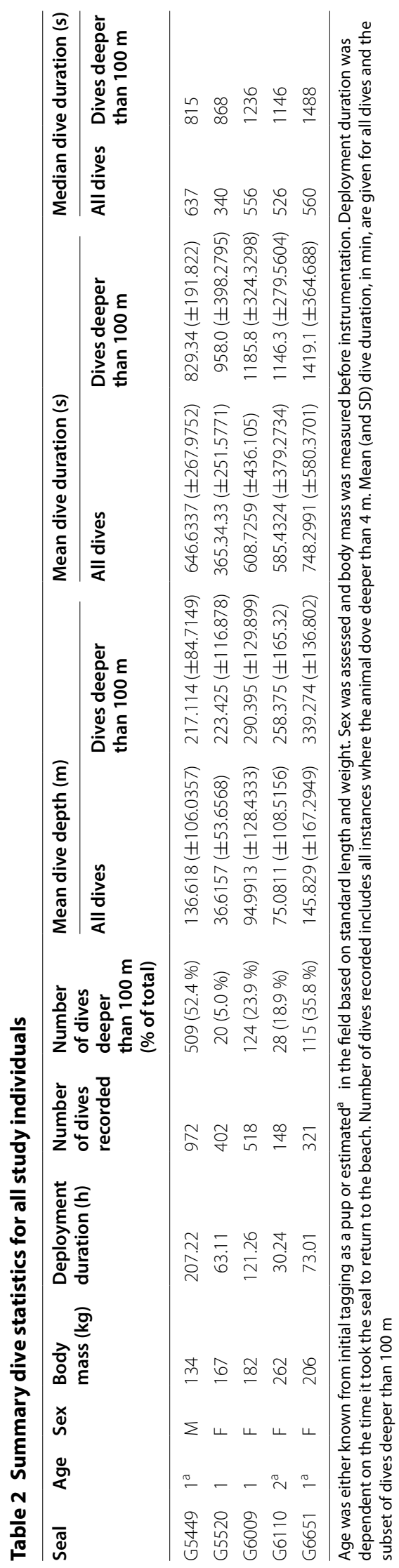


$\pm 1 \mathrm{~m}$. The accelerometer, magnetometer, and gyroscope were all sampled at $50 \mathrm{~Hz}$.

Playbacks occurred every $6 \mathrm{~h}$ for the first two seals and every $3 \mathrm{~h}$ for the remaining seals. Each playback consisted of one exposure to a single stimulus. The order of stimuli presentation varied between seals, but remained the same within an individual seal, unless the tag reset itself, at which point it started back at the beginning of the sequence.

\section{Behavioral analysis}

Passive recordings were screened for successful exposures (Table 3), and timing of exposures across multiple tag systems was synced. Depth data from the TDRs were examined for possible seal responses to exposures (Fig. 3). To account for zero offset drift, dive data were analyzed using the IKNOS toolbox (Y. Tremblay, unpublished) in MATLAB (MathWorks, Inc, Natick, MA, USA). Dives were defined as any instance where the individual dove deeper than $4 \mathrm{~m}$. This threshold was chosen to be greater than the sum of the accuracy of the TDR $( \pm 1 \mathrm{~m})$ and the body length of an individual.

We hypothesized that responses would differ according to dive type and state, so different dives and exposures were analyzed separately. Dive shapes were used to identify different dive types (e.g., transit vs. foraging [39]). Dives were grouped into deep $(>100 \mathrm{~m})$ and shallow $(\leq 100 \mathrm{~m})$ dives (Table 3$)$. Exposures were categorized by dive phase (descent, ascent, bottom phase, and surface; Table 3). Descents were defined as the segment from $0 \mathrm{~m}$ to the point at which the seal descended at a rate $<0.1 \mathrm{~m} \mathrm{~s}^{-1}$ for $20 \mathrm{~s}$. The beginning of an ascent was defined as the point at which an individual ascended for more than $4 \mathrm{~m}$ over $20 \mathrm{~s}$ (an ascent rate of $0.2 \mathrm{~m} \mathrm{~s}^{-1}$ ). Bottom phases were defined as the segment between the descending and ascending segments. Exposures that occurred at depths shallower than $20 \mathrm{~m}$ were labeled as "surface" and excluded from all analyses due to increased ambient noise levels, and thus a decreased signal-tonoise ratio of the low-level stimulus, near the water's surface.

To determine potential responses during ascent or bottom phases of deep $(>100 \mathrm{~m})$ dives, dive inversions (Fig. 4) were measured and compared. Dive inversions were defined as a change from ascending or horizontal swimming to descending, with a change in depth $>3 \mathrm{~m}$ over $4 \mathrm{~s}$. Change in depth and change in time from the inversion point to the next maximum depth were measured and normalized by maximum depth and total dive duration, respectively. In order to statistically compare dive inversions following exposures to dive inversions outside of exposure events, an Anderson-Darling k-sample (ADK; [40]) test was run on seal G6651, the only seal to receive multiple exposures during the ascending phase. The ADK test was selected because it is distribution free and does not rely on equal sample sizes; however, it requires that samples are taken from independent distributions, in this case, different seals. G5449 was chosen for comparison as it had the largest deployment duration and therefore the most non-exposure dive inversions. To first test whether different seals could be directly compared, an ADK test was used to compare non-exposure dive inversions for seals G6651 and G5449. The magnitude of the dive inversion following the single playback during the bottom phase of a deep dive was measured and reported.

Descent rates for descending phases of deep dives were measured and compared to identify possible responses during descents. Average descent rate over $60 \mathrm{~s}$ before and $60 \mathrm{~s}$ after exposure onset were calculated. A time window of $60 \mathrm{~s}$ was selected in order to differentiate sustained changes in descent rate from brief startle responses during the playback only. Because an increase in descent rate is considered a subtle response that likely happens regularly in non-exposure dives, statistical analysis of changes in descent rate was not performed.

Table 3 Deployment duration and number of exposures for the successful deployments of the prototype tag

\begin{tabular}{|c|c|c|c|c|c|c|c|c|c|}
\hline \multirow[t]{3}{*}{ Seal } & \multirow{3}{*}{$\begin{array}{l}\text { Exposure } \\
\text { interval (h) }\end{array}$} & \multirow{3}{*}{$\begin{array}{l}\text { Number of } \\
\text { exposures received }\end{array}$} & \multicolumn{7}{|c|}{ Exposures by dive stage } \\
\hline & & & \multicolumn{2}{|c|}{ Descent } & \multicolumn{2}{|c|}{ Bottom phase } & \multicolumn{2}{|c|}{ Ascent } & \multirow[t]{2}{*}{ Surface } \\
\hline & & & Deep & Shallow & Deep & Shallow & Deep & Shallow & \\
\hline G5449 & 3 & 6 & 2 & - & - & 1 & 1 & - & 2 \\
\hline G5520 & 3 & 2 & - & - & - & 1 & - & 1 & - \\
\hline G6009 & 6 & 2 & - & - & - & - & - & - & 2 \\
\hline G6110 & 6 & 4 & 1 & - & - & - & 1 & - & 2 \\
\hline G6651 & 3 & 24 & 7 & 1 & 1 & 3 & 7 & 1 & 4 \\
\hline
\end{tabular}

The number of exposures was dependent on the success of the tag and the length of the deployment. Exposures during descent, bottom phase, and ascent are the subset of exposures used for analysis in each respective phase, split by shallow $(<100 \mathrm{~m})$ and deep $(>100 \mathrm{~m})$ exposures. Surface exposures were excluded from analysis 

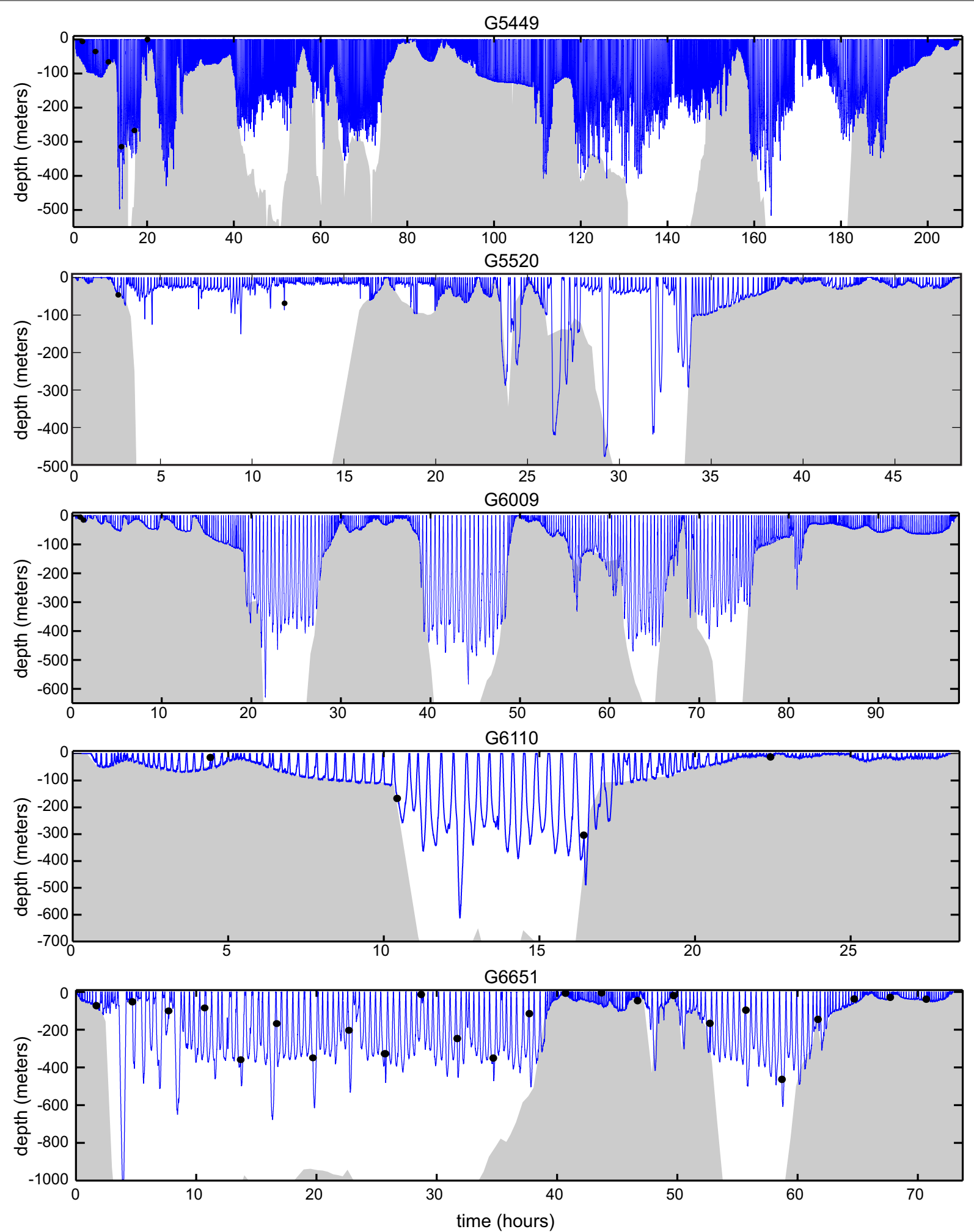

Fig. 3 Depth profiles and seafloor bathymetry for complete deployments for all seals. Seal dive profile is in blue, seafloor bathymetry is in gray, and exposures are indicated by black dots. Bathymetry data are from NOAA's NGDC, Southern California Coastal Relief Map, one-arc second resolution. Instances where a dive profile overlaps the seafloor are an artifact of data resolution mismatch; bathymetry data were extracted only for known GPS surface positions and linearly connected in the gray bathymetry plot, leading to areas with reduced detail 


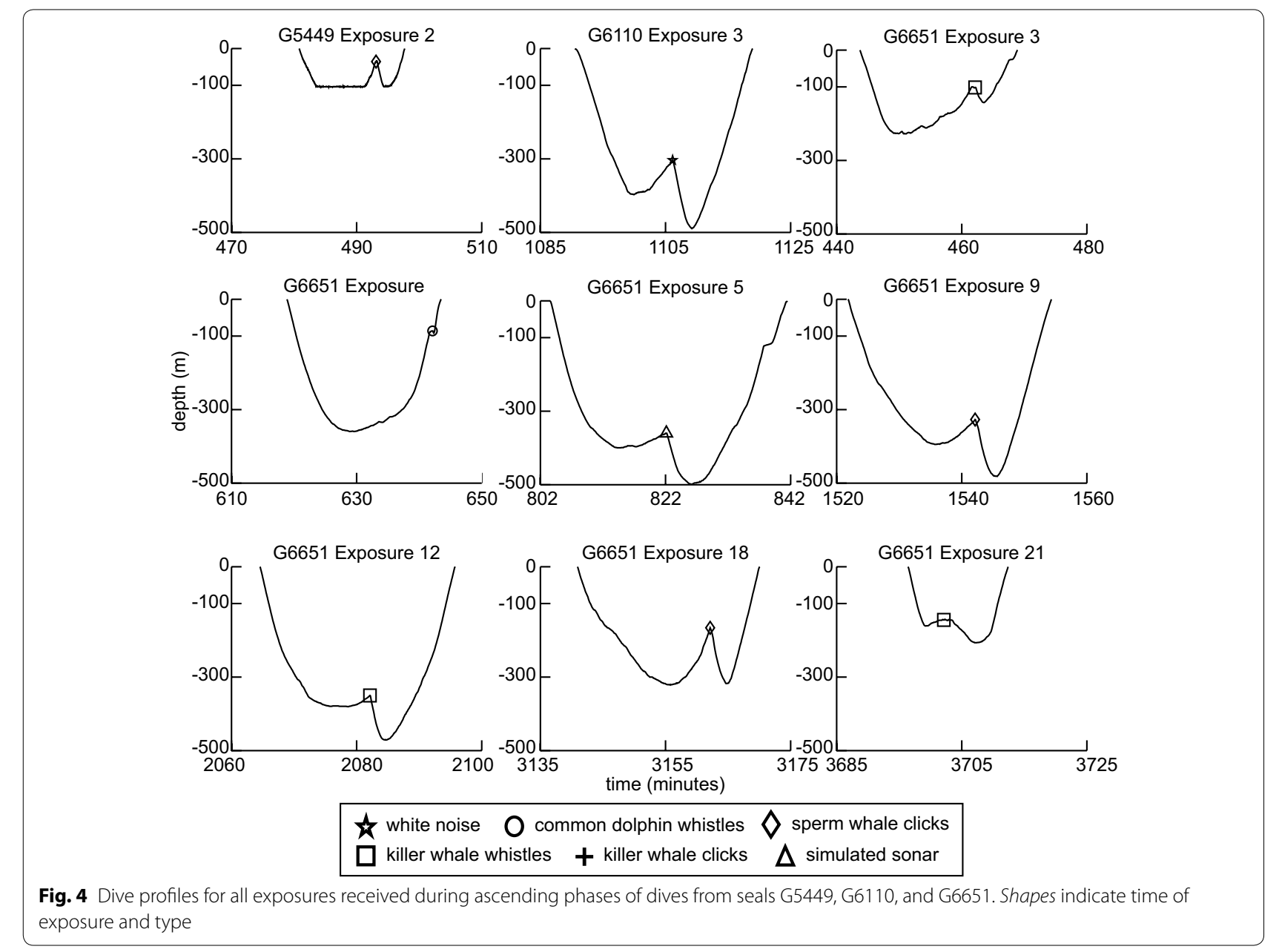

Shallow dives occurred along the shelf edge and were limited by the seafloor so diving deeper or reversing an ascent was not possible. To identify possible responses for these shallow dives, changes in flow noise on the passive acoustic recorder (a proxy for changes in swim speed) were measured and compared. Previous studies have found an 18- to 20 - $\mathrm{dB}$ increase at very low frequencies $(8-18 \mathrm{~Hz})$ corresponds to a doubling of current flow, regardless of tag or hydrophone design [34, 41]. Average RMS in the $8-18 \mathrm{~Hz}$ frequency band was measured for 30-60 and 0-30 s before exposure and 0-30 and 30-60 s after the exposure ended (Adobe Audition CC, Adobe Systems Incorporated, San Jose, CA, USA). The before and after periods were divided to detect shorter-term changes in swim speed, but the entire 60-s period was taken into account when assessing a response.

The normalized change in depth for exposure and non-exposure dive inversions for seal G6651 was plotted against time to investigate possible habituation to multiple playbacks over the duration of the deployment. To investigate differential response of all seals to different stimuli, each playback was categorized as either "response" or "no response," using a minimum level of response based on percent change, which varied for each dive state (ascending, bottom, descending, or shallow/ bottom-limited). Ascending or bottom-phase playbacks were categorized as "response" if there was a dive inversion magnitude $>2$ SDs from non-playback inversions. Descending playbacks were considered a response if descent rate increased by $>50 \%$ following exposure, and for shallow dives, an increase in flow noise of $>10 \%$ was considered a response. Percent of overall response was calculated.

\section{Results}

\section{Tag development}

Seven deployments of the prototype tag resulted in successful CEEs for five individuals (Table 2). Received levels at the individuals' ears, estimated from the source level and assuming spherical spreading, ranged from 128 to $138 \mathrm{~dB}$ re $1 \mu \mathrm{Pa}$, depending on seal and stimulus type. Mechanical (flooding) or electrical (tag control board 
reset) tag failure rendered the remaining two unsuccessful. The playback control of the tag would occasionally experience a reset for undetermined reasons, resulting in a stimulus that was played out of sequence. In some cases, this reset caused the tag to stop working entirely.

\section{Deployments and basic dive behavior}

Five successful deployments ranged from 30 to $207 \mathrm{~h}$ in duration. Animals received 2-24 playbacks, each a single 30-s exposure, at an interval of 3 or $6 \mathrm{~h}$, and nonexposure dives served as control dives (Table 3; Fig. 2). Four of five animals dove along the seafloor (depths up to $\sim 100 \mathrm{~m}$ ) until reaching the continental shelf edge, after which they exhibited deeper, pelagic transit dives with mean depths of 217-340 m over the deep water of Monterey Canyon. They returned to the shallow dive pattern when returning to shallow coastal waters near Año Nuevo State Park (Fig. 3). We found no evidence of foraging or drift dives, and the observed dive patterns were similar to those of other translocated juveniles [13, 42]. Dive depths $<100 \mathrm{~m}$ were likely limited by the seafloor, while deeper dives were not bottom-limited, which may have an effect on responses measured (Fig. 3) [43]. One individual (G5520) rarely dove deeper than $100 \mathrm{~m}(5.0 \%$ of all dives), even over deep water (Fig. 3). We found no significant difference in magnitude of non-exposure dive inversions for seals G5449 and G6651 (ADK, $p=0.14$, $n=283$ non-exposure inversions, seal G5449 and $n=30$ non-exposure inversions, seal G6651). Both exposures to seal G6009 were received at $<10 \mathrm{~m}$ depth, so they were excluded from further analyses. After this exclusion, there were 28 usable exposures on four seals, made up of 9 ascending, 10 descending, 1 bottom phase, and 8 shallow water exposures.

\section{Controlled exposure experiment}

We observed dive inversions following all playbacks that occurred during the ascending portion of a deep dive. Individuals descended an additional $116 \mathrm{~m}(\mathrm{SD} \pm 51.6 \mathrm{~m})$ on average (Fig. 4). 8 of 9 exposures resulted in changes in depth $>2$ SDs from the mean of all non-exposure inversions (Figs. 4, 5; Table 4). Seal G6651 was the only seal which received multiple exposures during ascent $(n=7$ exposures), and the magnitudes of dive inversions following these exposures were statistically different than nonexposure inversions (Fig. 5; Table 4; ADK test, $p<0.001$, $n=283$ non-exposure inversions, seal G5449 and $n=7$ exposure inversions, seal G6651). We observed this dive inversion response for white noise, sperm whale clicks, killer whale whistles, and simulated mid-frequency sonar exposure, but not following an exposure to common dolphins, received by seal G6651 (Fig. 4, G6651 Exposure 4). Seal G6651 was the only seal that received an exposure during the bottom phase of a deep dive $(351 \mathrm{~m})$. She dove to $614 \mathrm{~m}$ immediately following exposure, a $75 \%$ increase in maximum depth of dive (killer whale whistle exposure, Table 3).

Three seals received exposures during the descending phase of a deep dive, and two of three (G5549 and G6651) exhibited an increased descent rate (35.9-271.9\%; mean $125.2 \%$; $\pm 95.8 \%$ ) following exposure (Fig. 6; 9 of 10 total deep descending exposures). Seal G6110 had a lower descent rate following exposure to sonar $(72.7 \%$ decrease).

Flow noise (swim speed) increased by $10.0( \pm 8.0) \mathrm{dB}$ re $1 \mu \mathrm{Pa}$ from 0 to $30 \mathrm{~s}$ before exposure to $30-60 \mathrm{~s}$ after exposure (30.3 $\pm 14.7 \%$ increase) in all 8 exposures (to three seals) that occurred in shallow water $(<100 \mathrm{~m})$. For two of the exposures, flow noise initially decreased in the $0-30 \mathrm{~s}$ immediately after exposure but by $60 \mathrm{~s}$ after, reached above pre-exposure levels.

Dive inversion responses seal G6651 were as pronounced as or more pronounced than those later in the deployment compared to earlier (Fig. 7). Seals responded to 23 of 28 total exposures ( $82 \%$ ), regardless of stimulus type, indicating no differential response.

\section{Discussion}

We identify behavioral responses in juvenile northern elephant seals elicited by an animal-mounted sound source. This is the first dedicated BRS conducted on any marine mammal using an animal-borne sound source (see [44] for incidental BRS with an active sonar tag). This approach has the potential to expand and complement current CEE methodologies. Such data will provide enhanced understanding of longer-term effects of anthropogenic noise.

\section{Tag performance}

Deployments that resulted in unsuccessful or reduced duration CEEs were due to issues with either the SBC or the housing. We were unable to resolve the cause of the $\mathrm{SBC}$ reset, but believe it was caused by the formation of a ground loop due to differential ground potentials of the independent hardware components comprising the single tag system. Although the housing was rated to $1500 \mathrm{~m}$ depth, either changes in temperature and pressure with depth or incorrectly sized o-rings likely caused failure of the slightly flexible Delrin ${ }^{\circledR}$ housing, allowing seawater to enter the housing and short circuit the electronics. Future tags would benefit greatly from being potted in solid resin; however, the non-permanent setup used in this trial allowed us to monitor and modify physical tag components and programming as needed during the field effort. Additionally, we found no evidence of instrumentation or drag affecting normal swimming behavior, as 


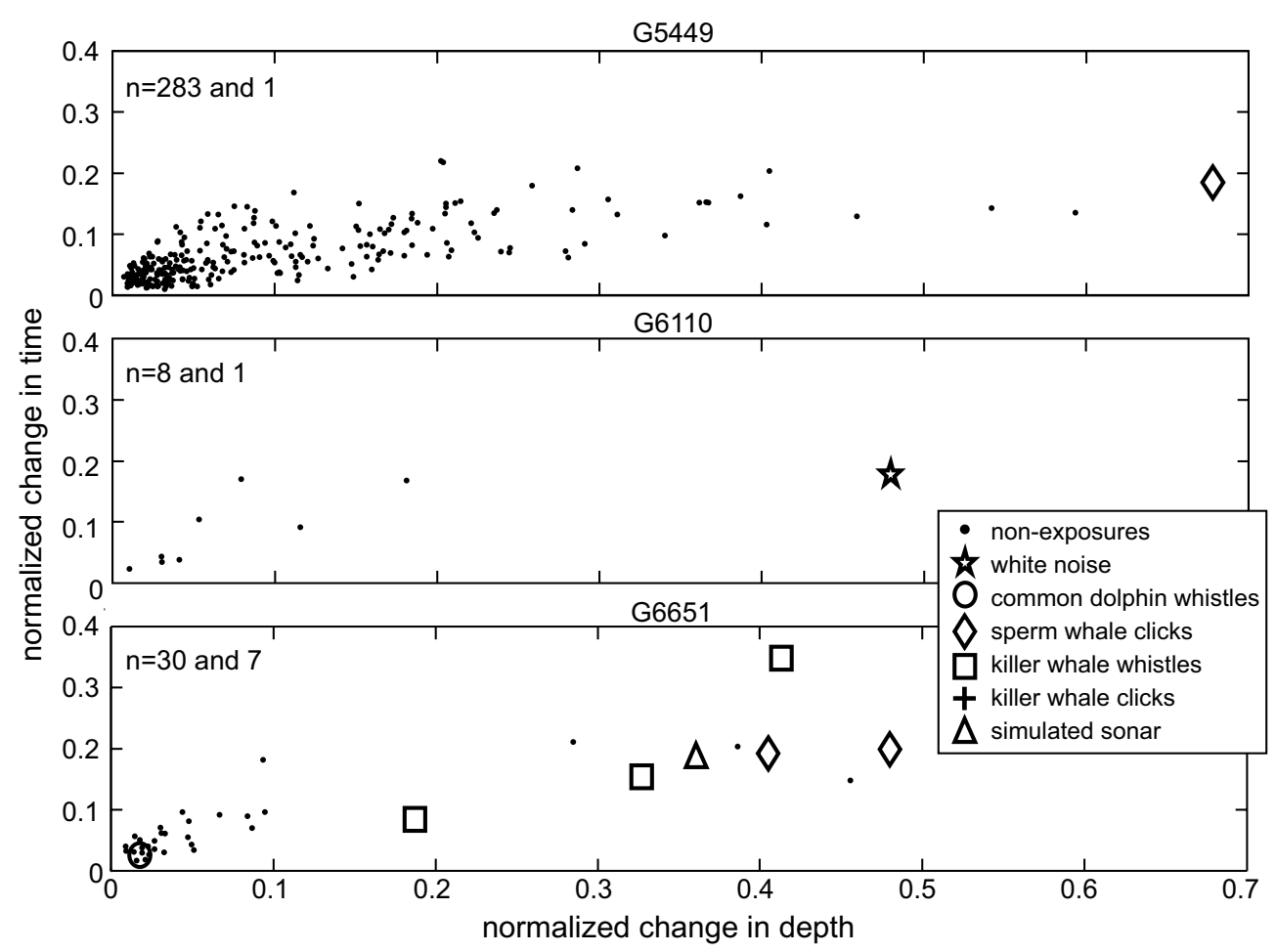

Fig. 5 Plot of normalized change in depth versus normalized change in time for all dive inversions during the ascending phase of all deep dives (>100 m) for seals G5449, G6110, and G6651. Black dots symbolize non-exposure dive inversions, and open symbols indicate dive inversions following exposures

Table 4 Mean change in depth for non-exposure and exposure dive inversions

\begin{tabular}{|c|c|c|c|c|c|}
\hline Seal & $\begin{array}{l}\text { Mean change in } \\
\text { non-exposure in }\end{array}$ & & $\begin{array}{l}\text { Mean change } \\
\text { for exposure ir }\end{array}$ & & Anderson-Darling k-sample test \\
\hline G5449 & $14.875( \pm 13.997)$ & $n=283$ & 70.5 & $n=1$ & $\mathrm{n} / \mathrm{a}$ \\
\hline G6110 & $16.749( \pm 16.293)$ & $n=8$ & 186 & $n=1$ & $\mathrm{n} / \mathrm{a}$ \\
\hline G6651 & $24.867( \pm 39.981)$ & $n=30$ & $96.36( \pm 59.23)$ & $n=7$ & $p=<0.001$ \\
\hline
\end{tabular}

Dive inversions are defined by a change from ascending to descending $>3 \mathrm{~m}$ over $4 \mathrm{~s}$, for all dives deeper than $100 \mathrm{~m}$. Standard deviation is given in parentheses, and $n$ is given for each. Results from an Anderson-Darling k-sample test comparing the change in depth of an inversion from ascending to descending, normalized by maximum depth of dive, for exposure inversions of seal G6651 to non-exposure inversions from seal G5449 ( $n=283)$ are given

dive profiles were similar to those of other translocated seals carrying smaller devices [13, 42, 45].

\section{Animal response to disturbance}

Behavioral responses measured during CEEs varied with dive state at the time of exposure. Most responses involved seals diving deeper and/or longer after exposure. The clearest responses (Fig. 4; Table 4) involved dive inversions (reversal of an ascent) followed by the seal diving deeper than the initial maximum dive depth. These extended dive inversions served as strong indicators of response. Quantitatively, dive inversions resulted in greater depths and longer dive durations, when compared to smaller-scale dive variations seen naturally in these and other translocated seals carrying a depth sensor [13, 46]. The exposure context here is unique in terms of the extreme proximity of the sound source to the animal, and the extrapolation of results to longer-range exposures should thus be considered cautiously. However, this context is more constant than in previous studies providing a stronger basis for the comparison of responses within an individual across exposure conditions.

Responses observed are similar to hypothesized elephant seal behavior to escape predators by diving deeper [37], and responses to anthropogenic sound sources are not unexpected [13, 44]. Responses elicited during CEEs 

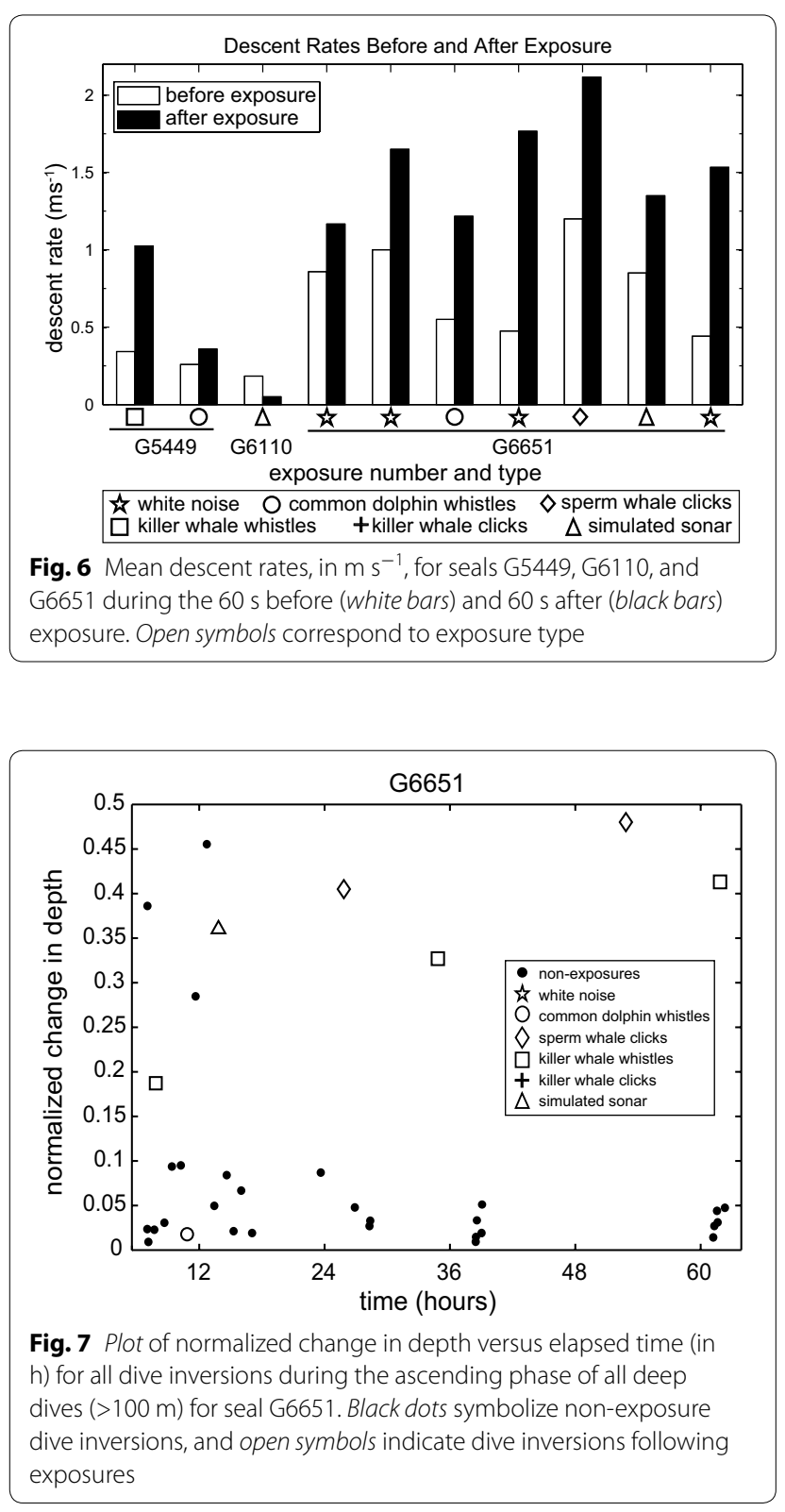

were similar to those found by other BRSs on deep-diving marine mammals. For instance, dive inversions and remaining at depth longer were demonstrated in two species of beaked whale exposed to simulated mid-frequency sonar from an external, ship-mounted sound source [22, 47]. A third species of beaked whale responded to exposures of both sonar and killer whale sounds by interrupting foraging and performing an unusually long and shallow ascent [12].

Responses to exposures that occurred during descents or during bottom-limited dives were more difficult to measure. Natural variation in swim speed and descent angle limited our ability to define statistical significance for observed responses. In future studies, initiating exposure during one dive phase would control experimental variability and allow robust statistical analyses of responses.

We suspect the tag reset described above, and the resulting stimulus playback, is the most likely explanation for three non-exposure dive inversions of similar magnitude to inversions following exposures observed in seal G6651 (Fig. 5). The inversions could have occurred naturally (e.g., exposure to an external alarming sound) or from an accidental exposure by the prototype tag following a reset; however, the independent passive acoustic system was not recording so we cannot know for sure. Continuous recording of ambient noise on future tag iterations, and longer-duration deployments, would allow for potential opportunistic measurement of behavioral responses to naturally occurring threatening sounds such as predators, boats, or other man-made or tag-made sounds.

\section{Differential response by stimulus type}

We found no indication of differential responses based on stimulus type or order (Table 5). Notably, seals responded to most $(82 \%)$ but not all exposures, indicating a possible differential response that was not detected because of limited sample size.

The observed results suggest that the response may be a result of acoustic limitations of the playback apparatus rather than the stimuli (see [48]). Limitations included the nonlinear nature of the small transducers and extreme proximity of the source to the animal. This proximity likely created an unusual perceptual context compared to a sound produced naturally at realistic ranges due to the effects of sound propagation (e.g., reverberation, directional cues, and the relative presence or absence of harmonics). Many details of pinniped underwater hearing, including directionality, are still poorly understood [36, 49,50]. Sudden sounds may trigger a response, regardless of the sound type or the distance it

Table 5 Differences in response rate by exposure type and for all exposures to all seals

\begin{tabular}{lcc}
\hline Exposure & Number of exposures & Response measured \\
\hline White noise & 6 & 5 \\
Common dolphin & 4 & 2 \\
$\quad$ whistles & & \\
Sperm whale clicks & 5 & 5 \\
Killer whale whistles & 6 & 5 \\
Killer whale click & 1 & 1 \\
Sonar & 6 & 5 \\
Total & 28 & 23 \\
\hline
\end{tabular}


is perceived to be coming from. Future testing using playback stimuli that are filtered to simulate different source locations could examine the effects of reverberation and localization in detail. Comparable parallel CEEs would need to be conducted on pinnipeds, using an external sound source that closely approximate actual signals, to fully evaluate the potential of this tag for BRS.

While individual differences could also contribute to different responses, no single seal received multiple exposures of all exposure types because of tag failures, which precludes further examination of this possibility. BRS exposing animals to multiple exposures of all stimuli are needed to investigate individual differences to stimuli. A differential response to dolphin whistles was recorded for seal G6651, the only seal exposed to two playbacks of dolphin whistles while ascending from a dive. No extreme dive inversions were recorded for dolphin whistles, while other stimuli resulted in extreme evasive behavior. This anecdotal example provides evidence for the possibility of differential response to different stimuli.

Repeated exposures to various stimuli may cause habituation over time [51]. Although there was no evidence of habituation over short-term deployments ( $<3$ days), we cannot rule out the possibility of a sensitization response. The consistent response to most exposures independent of stimulus type and the apparent lack of reduction in response within individuals suggest either that seals are generally sensitive to a relatively wide range of audible exposures or possibly that seals became sensitized to subsequent exposure. Preliminary evidence from captive elephant seals suggests some sensitization, as opposed to habituation, upon repeated exposure to certain acoustic stimuli [52]. However, the sound source placement, context, and limited number of exposures of each stimulus type to each individual limited our ability to test for potential sensitization.

The tag and method may be useful in physiological studies of dive limits and studies of hearing ranges. The tag could be used as a mobile, programmable sound source to study frequency-dependent hearing in marine mammal species that cannot be studied using captive psychophysical methods. Little is known about hearing in many marine mammals because laboratory studies of hearing are not feasible due to constraints with keeping very large, migratory, deep-diving, and social species in captivity, but using controlled, incrementally increasing exposure levels of tonal sounds that trigger drastic changes in behavior could investigate differences in hearing sensitivities in previously inaccessible species.

Additionally, this tag could be used to study the physiological effects of unanticipated extensions of dives, another important research need for understanding the effects of noise on marine mammals [18]. We are beginning to better understand how animals behaviorally respond to sound, but we still do not fully understand the underlying physiological changes that are linked to these behavioral changes (e.g., oxidative stress). Physiological parameters such as oxygen utilization, heart rate, and post-dive recovery times can be monitored in freeranging animals [53, 54], and with this tag, dives can be experimentally extended, allowing quantitative investigation of physiological responses. To support the potential use of this tag to study physiological effects of extended dives possibly related to responses to anthropogenic noise, it is promising that the responses were similar to other deep-diving species of interest. For species that are specialized for oxygen efficiency during prolonged, deep dives, physiological responses to changes in planned dive duration could help physiologists better understand these adaptations [55].

\section{Conclusions}

This pilot study was the first of its kind to investigate the potential use of an animal-borne sound source to conduct BRS on marine mammals to further investigate the effects of anthropogenic noise. Five juvenile northern elephant seals were instrumented and translocated south of their colony at Año Nuevo State Park. They received playbacks of multiple stimulus types (both man-made and natural) from the tag while diving continuously on their return to the colony. Dive behavior before and after exposures were compared to assess whether animal-borne tags holding sound sources were capable of eliciting a response from a free-ranging animal and whether potential responses differed with stimulus content.

Projecting sound from a tag mounted to the back of a free-ranging juvenile northern elephant seal did elicit behavioral responses; however, the responses were not consistently different with different stimulus types. Responses varied by seal, by dive state, and by the bathymetry where the exposure occurred, but in general, seals dove deeper following playback. Animals responded to $82 \%$ of exposures overall, with no clear evidence of a reduction in response to repeated exposures of various stimuli. The unique and biologically unrealistic context of a sudden sound exposure coming from directly behind the animal is likely the greatest limiting factor preventing use of this tag in examining differential responses to particular sounds and relating them to responses that may occur over more realistic source-animal ranges. Making conclusions about the effects of particular sounds on juvenile northern elephant seals was beyond the scope of this pilot study, but additional tests using this technology may help develop additional questions and hypotheses in the future. 
Tag improvements and additional field testing could strengthen results found here, but the concept of an animal-borne sound source for triggering behavioral responses has been validated. The use of this novel animal-borne sound source in future studies could help increase the ability to measure and evaluate the type and probability of response for various sound exposures within a constant context, connecting vital rates to longterm health effects, evaluating potential habituation or sensitization from repeated exposures, and even evaluating basic aspects of hearing (e.g., frequency ranges) for marine mammals previously unstudied. Each of these would represent important steps in better understanding the effects of anthropogenic noise on marine mammals.

\begin{abstract}
Abbreviations
ADK: Anderson-Darling k-sample; BRS: behavioral response study; CEE: controlled exposure experiment; ESA: Endangered Species Act; MMPA: Marine Mammal Protection Act; NGDC: National Geophysical Data Center; NMFS: National Marine Fisheries Service; NOAA: National Oceanic and Atmospheric Association; NRC: National Research Council; SBC: single board controller; TDR: time-depth recorder.
\end{abstract}

\section{Authors' contributions}

SF and HK were involved in securing funding, tag development, field work, analysis, and drafting the manuscript. MH provided field, analysis, and writing support. DPC provided field assistance and permitting. DM provided tag development and analysis support. KS participated in tag development and field efforts. LAH provided field and data analysis support. DKM helped secure funding and participated in tag development. BLS provided analysis, theory, and writing support. All authors read, edited, and approved the final manuscript.

\section{Author details}

${ }^{1}$ Cooperative Institute for Marine Resources Studies, Hatfield Marine Science Center, Oregon State University and NOAA Pacific Marine Environmental Laboratory, 2030 SE Marine Science Drive, Newport, OR 97365, USA. ${ }^{2}$ Bioacoustics Research Program, Cornell Laboratory of Ornithology, Cornell University, 159 Sapsucker Woods Road, Ithaca, NY 14850, USA. ${ }^{3}$ Marine Mammal Institute, Hatfield Marine Science Center, Oregon State University, 2030 SE Marine Science Drive, Newport, OR 97365, USA. ${ }^{4}$ Department of Ecology and Evolutionary Biology, University of California, Santa Cruz, 100 Shaffer Road, Santa Cruz, CA 95060, USA. ${ }^{5}$ Loggerhead Instruments, 6576 Palmer Park Circle, Sarasota, FL 34238, USA. ${ }^{6}$ The Sexton Corporation, 2130 Davcor St SE, Salem, OR 97302, USA. ${ }^{7}$ Southall Environmental Associates, 9099 Soquel Drive Suite 8, Aptos, CA 95003, USA. ${ }^{8}$ Long Marine Laboratory, Institute of Marine Sciences, University of California, Santa Cruz, 100 Shaffer Road, Santa Cruz, CA 95060, USA.

\begin{abstract}
Acknowledgements
We thank the students and volunteers of the Costa Laboratory at the University of California, Santa Cruz, for their assistance in the field, as well as Año Nuevo State Park and Barbara Block (Hopkins Marine Station, Stanford University). We thank Sharon Nieukirk, who provided insightful comments on the manuscript. We also thank the two anonymous reviewers for their thoughtful and constructive feedback. Field work was conducted under NMFS Permit \#87-1743 and approved under the University of California, Santa Cruz, IACUC AUP \#COSTD1409_A16. This is PMEL Manuscript \#4401. Field work and analysis were funded by a National Oceanic and Atmospheric Association (NOAA) National Marine Fisheries Service, Office of Science and Technology, Ocean Acoustics Program grant, the Oregon State University Cooperative Institute for Marine Resources Studies, and the Oregon State University Provost's Graduate Fellowship. Field work was further supported by the Office of Naval Research (Grant N00014-10-1-0356 to DPC).
\end{abstract}

\section{Competing interests}

The authors maintain no competing financial interests for this study.
Received: 30 October 2015 Accepted: 11 March 2016

Published online: 01 April 2016

\section{References}

1. Richardson WJ, Greene CR Jr, Malme Cl, Thomson DH, Greene CR, Malme $\mathrm{Cl}$, Thomson DH. Marine mammals and noise. San Diego: Academic Press; 1995.

2. Hildebrand JA. Anthropogenic and natural sources of ambient noise in the ocean. Mar Ecol Prog Ser. 2009;395:5-20.

3. Tournadre J. Anthropogenic pressure on the open ocean: the growth of ship traffic revealed by altimeter data analysis. Geophys Res Lett. 2014;41:7924-32.

4. Hildebrand JA. Impacts of anthropogenic sound. In: Reynolds III JE, Perrin WF, Reeves RR, Montgomery S, Ragen TJ, editors. Marine mammal research: conservation beyond crisis. Baltimore: The John Hopkins University Press; 2005. p. 101-24.

5. D'Amico A, Gisiner RC, Ketten DR, Hammock JA, Johnson C, Tyack PL, Mead J. Beaked whale strandings and naval exercises. Aquat Mamm. 2009;35:452-72.

6. Jepson PD, Arbelo M, Deaville R, Patterson IAP, Castro P, Baker JR, Degollada E, Ross HM, Herráez P, Pocknell AM, Rodríguez F, Howie FE, Espinosa A, Reid RJ, Jaber JR, Martin V, Cunningham AA, Fernández A. Gas-bubble lesions in stranded cetaceans. Nature. 2003;425:575-6.

7. Taylor B, Barlow J, Pitman R, Ballance L, Klinger T, DeMaster D, Hildebrand J, Urban J, Palacios D, Mead J. A call for research to assess risk of acoustic impact on beaked whale populations. PaperSC/56/E36 presented to the IWC Scientific Committee. Sorrento, Italy. 2004. p. 4. https://swfsc.noaa. gov/publications/CR/2004/2004Taylor1.pdf. Accessed 17 Mar 2016.

8. Nowacek DP, Johnson MP, Tyack PL. North Atlantic right whales (Eubalaena glacialis) ignore ships but respond to alerting stimuli. Proc Biol Sci. 2004;271:227-31.

9. Rolland RM, Parks SE, Hunt KE, Castellote M, Corkeron PJ, Nowacek DP, Wasser SK, Kraus SD. Evidence that ship noise increases stress in right whales. Proc R Soc B Biol Sci. 2012;279:2363-8.

10. Clark CW, Ellison WT, Southall BL, Hatch L, Van Parijs SM, Frankel A, Ponirakis $D$. Acoustic masking in marine ecosystems: intuitions, analysis, and implication. Mar Ecol Prog Ser. 2009;395:201-22.

11. Jones M, Swartz S, Dahlheim M. Census of gray whale abundance in San Ignacio Lagoon: a follow-up study in response to low whale counts recorded during an acoustic playback study. Report No. NTIS PB94195062 to the US Marine Mammal Commission. 1994. https://www.ntis. gov/Search/Home/titleDetail/?abbr=PB94195062. Accessed 17 Mar 2016.

12. Tyack PL, Zimmer WMX, Moretti $\mathrm{D}$, Southall BL, Claridge DE, Durban JW, Clark CW, D'Amico A, DiMarzio N, Jarvis S, McCarthy E, Morrissey R, Ward J, Boyd IL. Beaked whales respond to simulated and actual navy sonar. PLoS One. 2011;6:e17009.

13. Costa DP, Crocker DE, Gedamke J, Webb PM, Houser DS, Blackwell SB, Waples D, Hayes SA, Le Boeuf BJ. The effect of a low-frequency sound source (acoustic thermometry of the ocean climate) on the diving behavior of juvenile northern elephant seals, Mirounga angustirostris. J Acoust Soc Am. 2003;113:1155-65.

14. Weilgart LS. The impacts of anthropogenic ocean noise on cetaceans and implications for management. Can J Zool. 2007;85:1091-116.

15. International Whaling Commission. Report of the Scientific Committee. Annex K. Report of the standing working group on environmental concerns. J Cetacean Res Manag. 2007;9(Supp):227-96.

16. Tyack PL, Clark CW. Quick-look report: playback of low-frequency sound to gray whales migrating past the central California coast. 1998. http:// www.whoi.edu/fileserver.do?id $=57468 \& p t=10 \& p=40212$. Accessed 17 Mar 2016.

17. Southall B, Berkson J, Bowen D, Brake R, Eckman J, Field J, Gisiner R, Gregerson S, Lang W, Lewandoski J, Wilson J, Winokur R. Addressing the Effects of Human-Generated Sound on Marine Life: An Integrated Research Plan for U.S. federal agencies. Interagency Task Force on Anthropogenic Sound and the Marine Environment of the Joint Subcommittee on Ocean Science and Technology. Washington, DC. 2009. http://www. nmfs.noaa.gov/pr/pdfs/acoustics/jsost2009.pdf. Accessed 17 Mar 2016. 
18. National Research Council. Marine mammal populations and ocean noise: determining when noise causes biologically significant effects. Washington, DC: U.S. National Academy of Sciences; 2005.

19. Tyack PL. Acoustic playback experiments to study behavioral responses of free-ranging marine animals to anthropogenic sound. Mar Ecol Prog Ser. 2009;395:187-200.

20. Southall BL, Moretti D, Abraham B, Calambokidis J, DeRuiter SL, Tyack PL. Marine mammal behavioral response studies in Southern California: advances in technology and experimental methods. Mar Technol Soc J. 2012;46:48-59.

21. Curé C, Antunes R, Alves AC, Visser F, Kvadsheim PH, Miller PJO. Responses of male sperm whales (Physeter macrocephalus) to killer whale sounds: implications for anti-predator strategies. Sci Rep. 2013;3:1579.

22. DeRuiter SL, Southall BL, Calambokidis J, Zimmer WMX, Sadykova D, Falcone EA, Friedlaender AS, Joseph JE, Moretti D, Schorr GS, Thomas L, Tyack PL, Zimmer MX. First direct measurements of behavioural responses by Cuvier's beaked whales to mid-frequency active sonar. Biol Lett. 2013;9:20130223.

23. Goldbogen JA, Southall BL, DeRuiter SL, Calambokidis J, Friedlaender AS, Hazen EL, Falcone EA, Schorr GS, Douglas A, Moretti DJ, Kyburg C, McKenna MF, Tyack PL. Blue whales respond to simulated mid-frequency military sonar. Proc R Soc B Biol Sci. 2013;280:20130657.

24. Antunes R, Kvadsheim PH, Lam FPA, Tyack PL, Thomas L, Wensveen PJ, Miller PJO. High thresholds for avoidance of sonar by free-ranging longfinned pilot whales (Globicephala melas). Mar Pollut Bull. 2014;83:165-80.

25. Curé C, Sivle LD, Visser F, Wensveen PJ, Isojunno S, Harris CM, Kvadsheim PH, Lam FP, Miller PJO. Predator sound playbacks reveal strong avoidance responses in a fight strategist baleen whale. Mar Ecol Prog Ser. 2015;526:267-82

26. Gill T. On a new species of the genus Macrorhinus. Proc Chic Acad Sci. 1866;1:33-4.

27. Worthy GAJ, Morris PA, Costa DP, Le Boeuf BJ. Moult energetics of the northern elephant seal (Mirounga angustirostris). J Zool Soc Lond. 1992;227:257-65.

28. Le Boeuf BJ. Variation in the diving pattern of northern elephant seals with age, mass, sex, and reproductive condition. In: Le Boeuf BJ, Laws RM, editors. Elephant seals: population ecology, behavior, and physiology. Berkeley: University of California Press; 1994. p. 237-52.

29. Le Boeuf BJ, Naito Y, Huntley AC, Asaga T. Prolonged, continuous, deep diving by northern elephant seals. Can J Zool. 1989;67:2514-9.

30. Le Boeuf BJ, Crocker DE, Costa DP, Blackwell SB, Webb PM, Houser DS, Boeuf L, Le Boeuf BJ, Crocker DE, Costa DP, Blackwell SB, Webb PM, Houser DS. Foraging ecology of northern elephant seals. Ecol Monogr. 2000;70:353-82

31. Robinson PW, Simmons SE, Crocker DE, Costa DP. Measurements of foraging success in a highly pelagic marine predator, the northern elephant seal. J Anim Ecol. 2010;79:1146-56.

32. Robinson PW, Costa DP, Crocker DE, Gallo-Reynoso JP, Champagne CD, Fowler MA, Goetsch C, Goetz KT, Hassrick JL, Hückstädt LA, Kuhn CE, Maresh JL, Maxwell SM, McDonald Bl, Peterson SH, Simmons SE, Teutschel NM, Villegas-Amtmann S, Yoda K. Foraging behavior and success of a mesopelagic predator in the northeast Pacific Ocean: insights from a data-rich species, the northern elephant seal. PLoS One. 2012;7:e36728.

33. Fletcher S, Le Boeuf BJ, Costa DP, Tyack PL, Blackwell SB. Onboard acoustic recording from diving northern elephant seals. J Acoust Soc Am. 1996;100:2531-9.

34. Burgess WC, Tyack PL, Le Boeuf BJ, Costa DP. A programmable acoustic recording tag and first results from free-ranging northern elephant seals. Deep Res Part II Top Stud Oceanogr. 1998;45:1327-51.

35. Kastak D, Schusterman RJ. In-air and underwater hearing sensitivity of a northern elephant seal (Mirounga angustirostris). Can J Zool. 1999;77:1751-8.

36. Reichmuth C, Holt MM, Mulsow J, Sills JM, Southall BL. Comparative assessment of amphibious hearing in pinnipeds. J Comp Physiol A. 2013;199:491-507.
37. Le Boeuf BJ, Crocker DE. Diving behavior of elephant seals: implications for predator avoidance. In: Klimley AP, Ainley DG, editors. Great white sharks: the biology of Carcharodon carcharias. San Diego: Academic Press; 1996. p. 193-205.

38. Le Boeuf BJ, Costa DP, Huntley AC, Feldkamp SD. Continuous, deep diving in female northern elephant seals, Mirounga angustirostris. Can J Zool. 1988;66:446-58.

39. Le Boeuf BJ, Crocker DE, Blackwell SB, Morris PA, Thorson PH. Sex differences in diving and foraging behaviour of northern elephant seals. Symp Zool Soc Lond. 1993;66:149-78.

40. Trujillo-Ortiz A, Hernandez-Walls R, Barba-Rojo K, Cupal-Magana L, ZavalaGarcia RC. AnDarksamtest: Anderson-Darling k-sample procedure to test the hypothesis that the populations of the drawned groups are identical. 2007. http://www.mathworks.com/matlabcentral/fileexchange/loadFile. do?objectld=17451. (Accessed 20 Jan 2015).

41. Finger RA, Abbagnaro LA, Bauer BB. Measurements of low-velocity flow noise on pressure and pressure gradient hydrophones. J Acoust Soc Am. 1979:65:1407-12.

42. Oliver GW, Morris PA, Thorson PH, Le Boeuf BJ. Homing behavior of juvenile northern elephant seals. Mar Mammal Sci. 1998;14:245-56.

43. Tremblay $Y$, Cherel $Y$. Benthic and pelagic dives: a new foraging behaviour in rockhopper penguins. Mar Ecol Prog Ser. 2000;204:257-67.

44. Lawson GL, Hückstädt LA, Lavery AC, Jaffré FM, Wiebe PH, Fincke JR, Crocker DE, Costa DP. Development of an animal-borne "sonar tag" for quantifying prey availability: test deployments on northern elephant seals. Anim Biotelem. 2015;3:22.

45. Maresh JL, Simmons SE, Crocker DE, McDonald BI, Williams TM, Costa DP. Free-swimming northern elephant seals have low field metabolic rates that are sensitive to an increased cost of transport. J Exp Biol. 2014;217:1485-95.

46. Davis RW, Fuiman LA, Williams TM, Le Boeuf BJ. Three-dimensional movements and swimming activity of a northern elephant seal. Comp Biochem Physiol Part A. 2001:129:759-70.

47. Stimpert AK, DeRuiter SL, Southall BL, Moretti DJ, Falcone EA, Goldbogen JA, Friedlaender AS, Schorr GS, Calambokidis J. Acoustic and foraging behavior of a tagged Baird's beaked whale (Berardius bairdii) exposed to simulated sonar. Sci Rep. 2014;4:7031.

48. Ellison WT, Southall BL, Clark CW, Frankel AS. A new context-based approach to assess marine mammal behavioral responses to anthropogenic sounds. Conserv Biol. 2012;26:21-8.

49. Terhune JM. Directional hearing of a harbor seal in air and water. J Acoust Soc Am. 1974;56:1862-5.

50. Nummela S. Hearing in aquatic mammals. In: Thewissen JGM, Nummela $\mathrm{S}$, editors. Sensory evolution on the threshold: adaptations in secondarily aquatic vertebrates. Berkeley: University of California Press; 2008. p. 211-24.

51. Bowles AE, Anderson RC. Behavioral responses and habituation of pinnipeds and small cetaceans to novel objects and simulated fishing gear with and without a pinger. Aquat Mamm. 2012;38:161-88.

52. Kastak DA. Comparative aspects of hearing in pinnipeds. Santa Cruz: University of California; 1996.

53. Meir JU, Champagne CD, Costa DP, Williams CL, Ponganis PJ. Extreme hypoxemic tolerance and blood oxygen depletion in diving elephant seals. Am J Physiol Regul Integr Comp Physiol. 2009;297:R927-39.

54. Meir JU, Robinson PW, Ignacio Vilchis L, Kooyman GL, Costa DP, Ponganis PJ. Blood oxygen depletion is independent of dive function in a deep diving vertebrate, the northern elephant seal. PLoS One. 2013;8:8-13.

55. Davis RW, Williams TM. The marine mammal dive response is exercise modulated to maximize aerobic dive duration. J Comp Physiol A. 2012;198:583-91. 